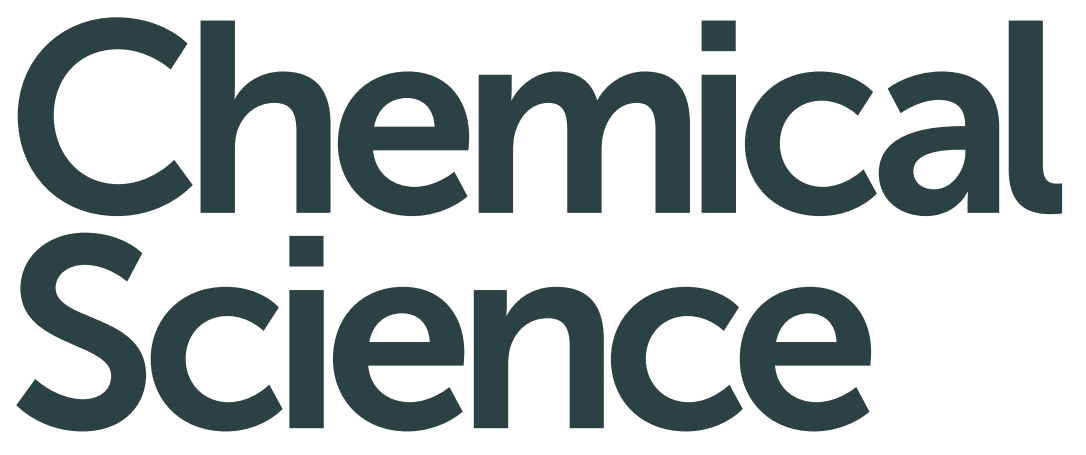

rsc.li/chemical-science

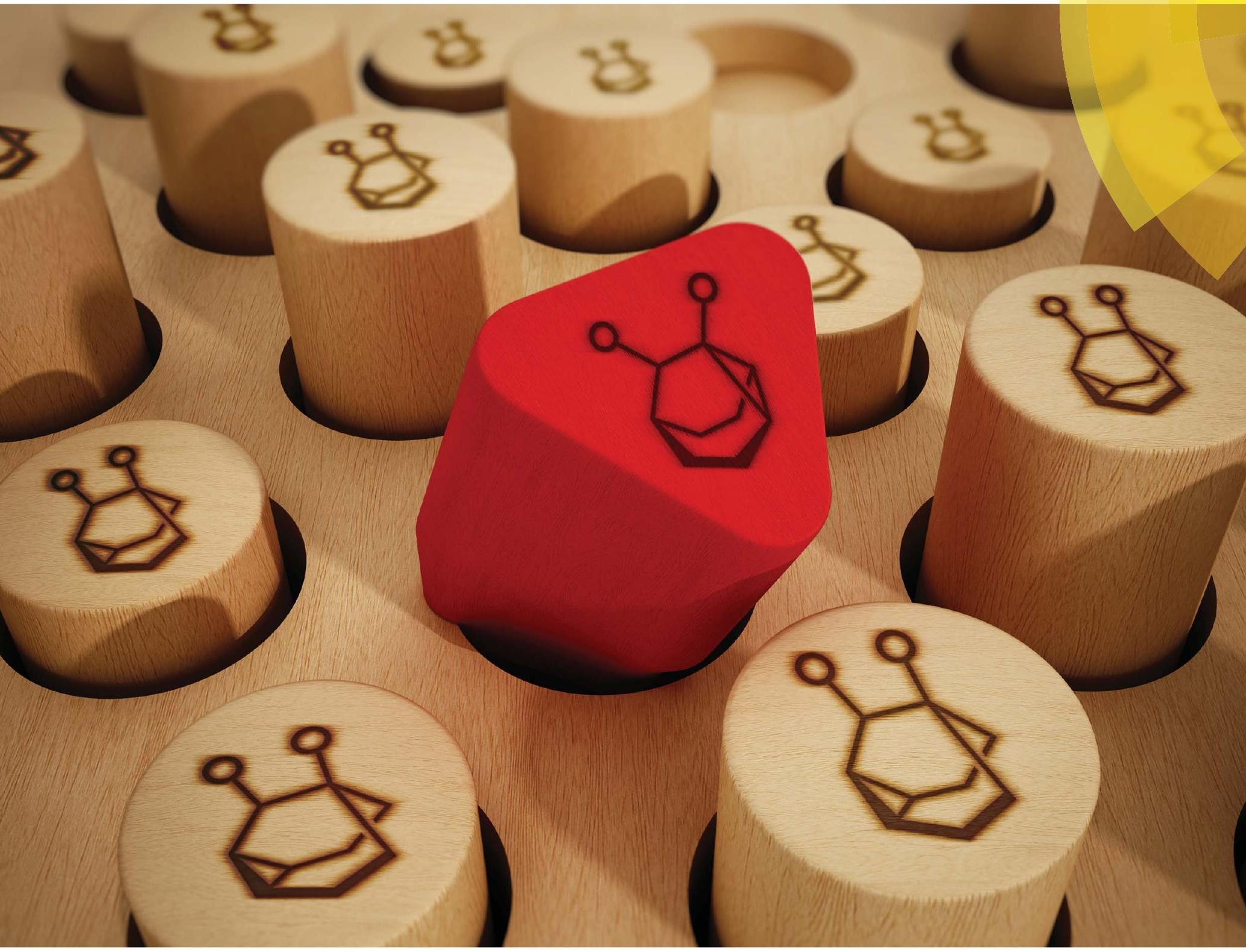

ISSN 2041-6539

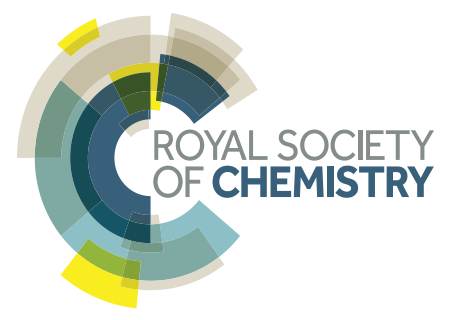


Check for updates

Cite this: Chem. Sci., 2018, 9, 8631

๑ All publication charges for this article have been paid for by the Royal Society of Chemistry

Received 27th September 2018 Accepted 19th October 2018

DOI: $10.1039 / \mathrm{c} 8 \mathrm{sc} 04303 \mathrm{e}$

rsc.li/chemical-science

\section{Shape-selective crystallisation of fluxional carbon cages $\uparrow$}

\author{
Aisha N. Bismillah, (D) Jiri Sturala, (D) B Brette M. Chapin, Dmitry S. Yufit, \\ Paul Hodgkinson (D) and Paul R. McGonigal (DD *
}

Dynamic covalent rearrangements of fluxional carbon cages, such as bullvalenes and barbaralanes, impart 'shapeshifting' molecular properties. Here, a series of five barbaralanes each interconvert dynamically between two constitutional isomers in solution, but resolve to single isomers upon crystallisation. Unexpectedly, the minor solution-phase isomers are resolved in two instances. Through dynamic NMR, crystallographic and DFT analyses, we show that the isomer observed in the solid state is not a direct consequence of the equilibrium distribution in solution or any specific noncovalent interactions. Rather, the dynamic preferential crystallisation is dictated by differences in molecular size and shape.

\section{Introduction}

Fluxional carbon cages, such as bullvalene ${ }^{1}$ and the barbaralyl cation $^{2}$ (Fig. 1a), undergo reversible pericyclic rearrangements on a grand scale. ${ }^{3}$ Sequential, low-energy steps interconvert large numbers of degenerate isomers. For example, bullvalene passes back and forth between 1.2 million degenerate valence isomers ${ }^{1}$ by strain-assisted Cope rearrangements. Functionalised derivatives, on the other hand, give rise (Fig. 1b) to nondegenerate valence isomers with distinct constitutions. ${ }^{4}$ When their $\mathrm{C}-\mathrm{C}$ bonds trade places with one another, the positions and relative orientations of their substituents are altered, endowing them with dynamic shapes (Fig. 1c) and making them ideal building blocks for adaptive chemistry. ${ }^{5}$ Bode et al. ${ }^{6}$ have taken advantage of these phenomena to design shapeshifting bullvalene sensors-the equilibrium distribution of tetrasubstituted bullvalene isomers is shifted in a characteristic manner when interacting with different guests, either by specific noncovalent interactions ${ }^{6 b}$ or dynamic covalent bonds. ${ }^{6 c}$

Here, we report on the influence of shape over the crystallisation of fluxional carbon cages. Neutral barbaralane derivatives, which equilibrate (Fig. 1b) between sets of two nonequivalent valence isomers ${ }^{7}$ in solution, are resolved to single valence isomers upon crystallisation. By analysing NMR spectra of solutions and powdered samples, X-ray crystal structures and

Department of Chemistry, Durham University, Lower Mountjoy, Stockton Road, Durham,DH13LE, UK. E-mail: paul.mcgonigal@durham.ac.uk

$\dagger$ Electronic supplementary information (ESI) available. CCDC 1857573-1857583, 1857874. For ESI and crystallographic data in CIF or other electronic format see DOI: $10.1039 / \mathrm{c} 8 \mathrm{sc} 04303 \mathrm{e}$

\$ Present address: Department of Inorganic Chemistry, University of Chemistry and Technology Prague, Technická 5, Prague 6 16628, Czech Republic.
DFT models, we observe that (i) the dynamic isomerism is 'frozen' in the solid state and (ii) relatively small differences in the substituents dictate which constitutional isomer is found upon crystallisation. Three of the compounds crystallise as the major solution-phase valence isomers, i.e., their molecular structures in the solid state match those of the thermodynamically favoured species in solution. However, two compounds crystallise (Fig. 1c) as the minor solution-phase valence isomers, achieving more densely packed crystals by adopting molecular structures that fit together more effectively. Size- and shapematching of these fluxional molecules to their surroundings outweigh the inherent energetic preference of the shapeshifting equilibrium. a

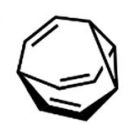

C

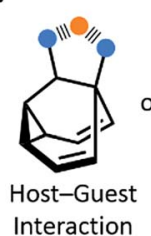

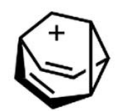

b
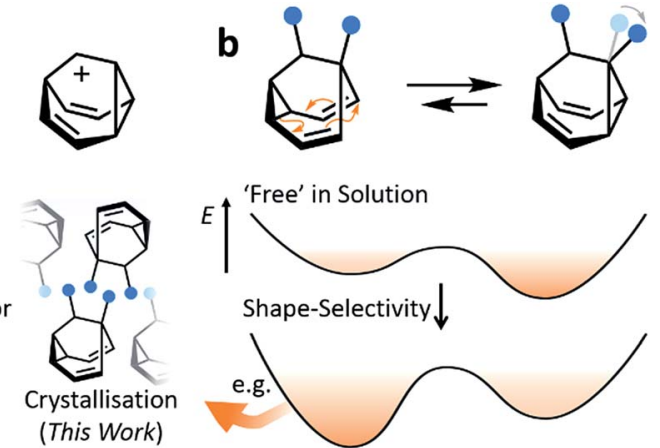

Fig. 1 Structural formulas of (a) bullvalene, the barbaralyl cation and (b) a disubstituted barbaralane, showing its isomerisation. The relative orientations of the substituents, which are represented by blue circles, are altered by the isomerisation. (c) A schematic representation illustrates changes in relative energies of isomers in panel $b$ as a result of a shape-selective intermolecular contact, e.g., through noncovalent bonding with a guest, represented as an orange circle, or by crystal packing. 


\section{Results and discussion}

We synthesised (Scheme 1) fluxional mixtures of nondegenerate barbaralanes $\mathbf{1} / \mathbf{1}^{\prime}$ in two steps from alkynyl cycloheptatriene precursors 2 (for experimental details see the ESI $\dagger$ ). Goldcatalysed cycloisomerisation of 2 proceeds ${ }^{2 c}$ through barbaralyl cation intermediates, which are oxidised ${ }^{2 d}$ in situ by $\mathrm{Ph}_{2} \mathrm{SO}$ to afford barbaralones 3 in $58-75 \%$ yields. Subsequent addition of arylmagnesium bromides to 3 gives barbaralanes $\mathbf{1} / \mathbf{1}^{\prime}$, each bearing a tertiary alcohol $\S$ and two aromatic rings. The aromatic ring at the $1 / 5^{\prime}$-position of each barbaralane breaks the symmetry of the Cope rearrangements, giving rise to the pairs of valence isomers $\mathbf{1}$ and $\mathbf{1}^{\prime}$. We reasoned that these pairs of nondegenerate valence isomers would be useful compounds for probing the shapeshifting properties of fluxional carbon cages. Compared to the huge numbers of valence isomers accessible to other systems, analysis of the double-well-type potential energy surface (Scheme 1) of $\mathbf{1 / \mathbf { 1 } ^ { \prime }}$ is more tractable. At the same time, the rearrangement still modulates the molecular shape to some extent-the strain present in the tricyclic cores of $\mathbf{1}$ and $\mathbf{1}^{\prime}$ is slightly different, regulating the relative orientations of the two aromatic rings. Five sets of barbaralanes $\left(\mathbf{1 a}-\mathbf{e} / \mathbf{1} \mathbf{a}^{\prime}-\mathbf{e}^{\prime}\right)$ were prepared in which the groups at the $p$-positions of the aromatic rings $\left(\mathrm{R}^{1}\right.$ and $\left.\mathrm{R}^{2}\right)$ are varied between OMe, $\mathrm{F}$, and $\mathrm{H}$.

Isomers 1 and $\mathbf{1}^{\prime}$ are in fast exchange (Fig. S15-S48†) when observed by solution-phase NMR spectroscopy. Consequently, each pair of exchangeable sites gives rise to one peak. The chemical shift of each peak represents an average of the two discrete chemical environments, weighted by the position of the equilibrium, which enables us to identify the major isomer. For example, the ${ }^{13} \mathrm{C}$ peak associated with position 2 of $\mathbf{1 a}$ and position $4^{\prime}$ of $\mathbf{1 a}^{\prime}$ appears (Fig. S16 $\dagger$ ) at $49.6 \mathrm{ppm}$ in $\mathrm{CDCl}_{3}$ at $298 \mathrm{~K}$, which is closer to the resonance of a divinyl cyclopropane group $^{8}(\sim 25 \mathrm{ppm})$ than that of a cis-dialkylolefin group ${ }^{9}$ ( 135 ppm). This observation allows us to assign 1a as the

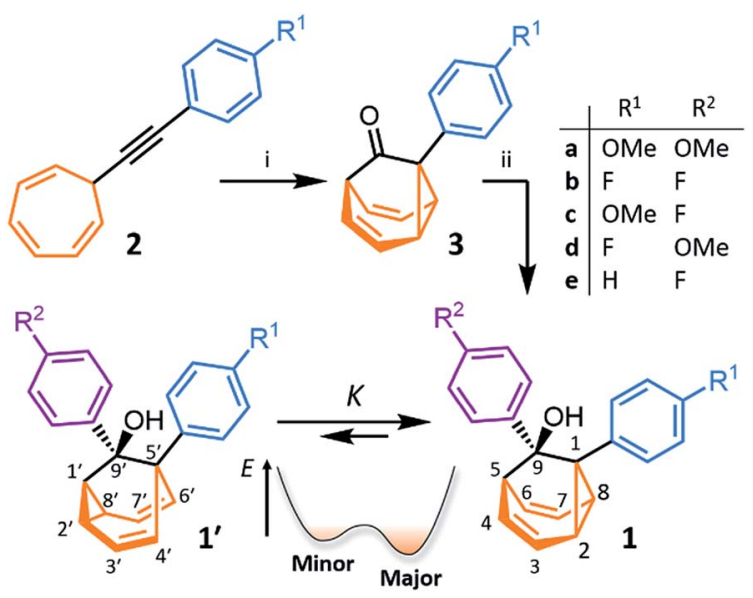

Scheme 1 Synthesis of fluxional carbon cages $1 / 1^{\prime}$. Reagents and conditions: (i) IPrAu(MeCN)BF 4 (5 mol\%), $\mathrm{Ph}_{2} \mathrm{SO}$ (2 equiv.), $\mathrm{CH}_{2} \mathrm{Cl}_{2}, \mathrm{rt}$, $16 \mathrm{~h}, 58-75 \%$; (ii) $p-\mathrm{R}^{2} \mathrm{C}_{6} \mathrm{H}_{4} \mathrm{MgBr}$, THF, $0{ }^{\circ} \mathrm{C}$ to rt, $16 \mathrm{~h}, 43-96 \%$. A schematic potential energy diagram illustrates the equilibrium, $K$, between $1^{\prime}$ and 1 . IPr $=1,3$-bis(2,6-diisopropylphenyl)imidazol-2ylidene. major isomer ${ }^{10}$ and to estimate an equilibrium constant, $K$, of $\sim 3.5$, as well as a Gibbs free energy difference, $\Delta G$, of $\sim 3 \mathrm{~kJ} \mathrm{~mol}^{-1}$. These conclusions are supported by DFT modelling, which predicts (Table S5†) that 1a is lower in energy than $\mathbf{1 a}^{\prime}$ by a margin of $\sim 5 \mathrm{~kJ} \mathrm{~mol}^{-1}$ (for calculation details see the ESI $\dagger$ ). Further NMR and DFT analyses reveal (Fig. S17-S48 and Table $\mathrm{S} 5 \dagger$ ) that $K$ is only minimally affected by varying the $\mathrm{R}^{1}$ and $\mathrm{R}^{2}$ groups at the $p$-positions of the aromatic rings. The substituents are sufficiently remote from the barbaralane core that their electronic and steric differences have little impact structure 1 remains the thermodynamically favoured solutionphase valence isomer for all derivatives (1a-e). In order to probe the equilibria further, we also recorded solution-phase ${ }^{1} \mathrm{H}$ NMR spectra of bis(4-anisyl)barbaralane 1a/1a' (Fig. S29†) and bis(4-fluorophenyl)barbaralane $\mathbf{1 b} / \mathbf{1} \mathbf{b}^{\prime}$ (Fig. 2) at low temperatures. The temperature-dependent spectroscopic changes are consistent with the behaviour of two nondegenerate valence isomers interconverting rapidly through a low-lying transition state. For example, the signal for the $8 / 6^{\prime}$ positions of $\mathbf{1 b} / \mathbf{1} \mathbf{b}^{\prime}$ shifts (Fig. 2) from $3.55 \mathrm{ppm}$ at $292 \mathrm{~K}$ to $3.31 \mathrm{ppm}$ at $165 \mathrm{~K}$, moving further towards the chemical shift expected for a cyclopropyl resonance, while the signal associated with $6 / 8^{\prime}$ moves towards the olefinic region, shifting from $5.50 \mathrm{ppm}$ at $292 \mathrm{~K}$ to $5.60 \mathrm{ppm}$ at $149 \mathrm{~K}$. Therefore, the equilibrium shifts further in favour of the thermodynamically favoured isomer $\mathbf{1 b}$ at lower temperatures, which would be expected for a Boltzmann distribution of nondegenerate isomers.

All five $\mathbf{1} / \mathbf{1}^{\prime}$ derivatives form crystalline solids, allowing us to analyse (Fig. 3) their solid-state structures by single-crystal X-ray diffraction. $\dagger$ The fluxional mixtures of $\mathbf{1} / \mathbf{1}^{\prime}$ undergo dynamic preferential crystallisation, ${ }^{\mathbf{1 1}}$ i.e., just one valence isomer from each pair of fluxional carbon cages crystallises from the mixture. ${ }^{12,13}$ The bis(4-anisyl)barbaralane crystallises (Fig. 3a) as the major solution-phase valence isomer 1a. Similarly, the barbaralanes bearing one 4-fluorophenyl group and one 4-anisyl group each adopt the major solution-phase structures 1c and 1d upon crystallisation. Surprisingly, however, we observed the more strained molecular structures in crystals of the bis(4fluorophenyl)barbaralane $\mathbf{1} \mathbf{b}^{\prime}$ and its phenyl analogue $\mathbf{1 e}^{\prime}$.

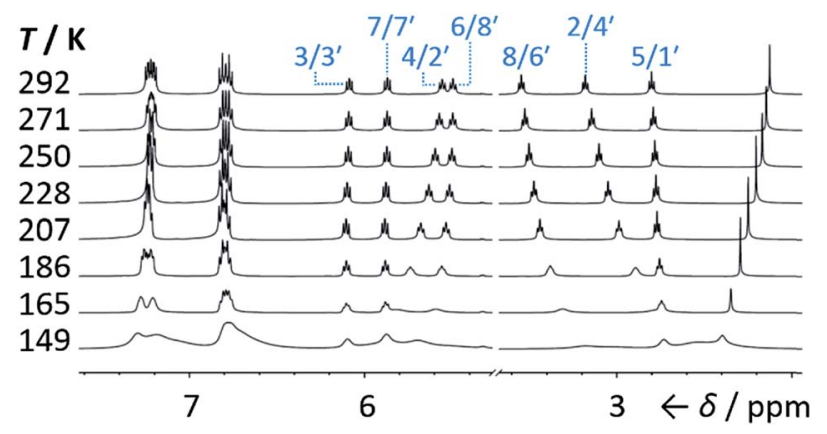

Fig. 2 Partial ${ }^{1} \mathrm{H}$ NMR spectra $\left(500 \mathrm{MHz}, \mathrm{CS}_{2}-\mathrm{CD}_{2} \mathrm{Cl}_{2}\right)$ of $1 \mathrm{~b} / 1 \mathrm{~b}^{\prime}$. As the temperature is decreased, the equilibrium shifts towards the lowerenergy isomer $1 \mathrm{~b}$. At temperatures below $186 \mathrm{~K}$, the broadening of peaks indicates the reversible Cope rearrangement is entering the slow-exchange regime. Selected resonances are labelled according to the numbering in Scheme 1. 

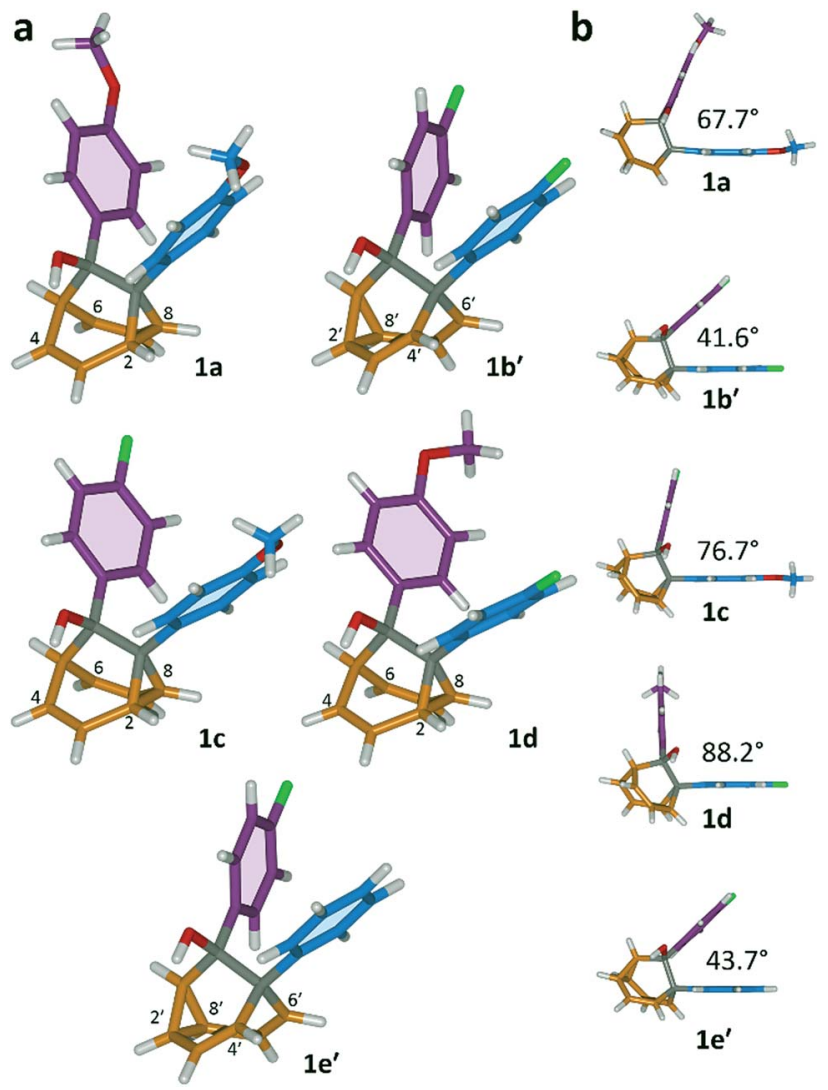

Fig. $3 X$-ray crystal structures of $1 / 1^{\prime}$ shown in stick representations. $\dagger$ (a) Whereas the major solution-phase valence isomers are obtained in some cases ( $1 \mathrm{a}, 1 \mathrm{c}$ and $1 \mathrm{~d})$, the minor solution-phase isomers crystallise preferentially in others $\left(1 \mathbf{b}^{\prime}\right.$ and $\left.1 \mathrm{e}^{\prime}\right)$. (b) Side-on views show the variation in dihedral angles between the planes of the aromatic rings.

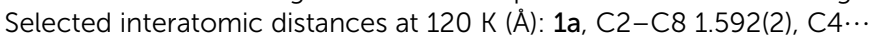
C6 2.359(2); 1b', C2'-C8' 1.592(3), C4'‥C6' 2.353(2); 1c, C2-C8

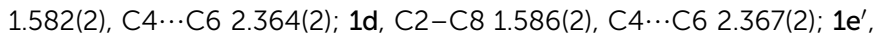
$C 2^{\prime}-C 8^{\prime} 1.591(2), C 4^{\prime} \cdots C 6^{\prime} 2.345(2)$. Oxygen atoms are shown in red, fluorine atoms are green, hydrogen atoms are white, and carbon atoms are blue, purple, orange or grey.

While the $p$-substituents have little influence over the solutionstate valence isomerism of the five $\mathbf{1} / \mathbf{1}^{\prime}$ derivatives, it appears that a subtle change at a position distant from the barbaralane core, such as switching out the OMe group of $\mathbf{1 c} / \mathbf{1} \mathrm{c}^{\prime}$ for a $\mathrm{F}$ atom (i.e., giving $\mathbf{1} \mathbf{b} / \mathbf{1} \mathbf{b}^{\prime}$ ), is sufficient to bias crystallisation in favour of another valence isomer. 9

Although some fluxional carbon cages $^{\mathbf{1 4}}$ are known to become 'fixed' structures upon crystallisation, others ${ }^{\mathbf{1 5}}$ remain fluxional. Variable-temperature X-ray diffraction (VT-XRD) measurements performed on single crystals of $\mathbf{1 a}$ and $\mathbf{1 b}^{\prime}$ show (Fig. S42 and S43†) negligible changes in C-C distances of bonds involved in Cope rearrangement. For example, the C2-C8 bond length of $1 \mathrm{a}$ only changes from $1.592 \AA$ at $120 \mathrm{~K}$ to $1.604 \AA$ at $370 \mathrm{~K}$. The identities of $\mathbf{1}$ and $\mathbf{1}^{\prime}$ isomers in the solid state can also be distinguished by comparing (Fig. 4) their lowtemperature solution and ambient-temperature solid-state ${ }^{13} \mathrm{C}$ NMR spectra. At $149 \mathrm{~K}$, the solution-phase equilibria are biased heavily towards $\mathbf{1 a}$ and $\mathbf{1 b}$, so both solution-phase spectra show (Fig. 4a,d) similar patterns of peaks in their alkyl regions. Unlike

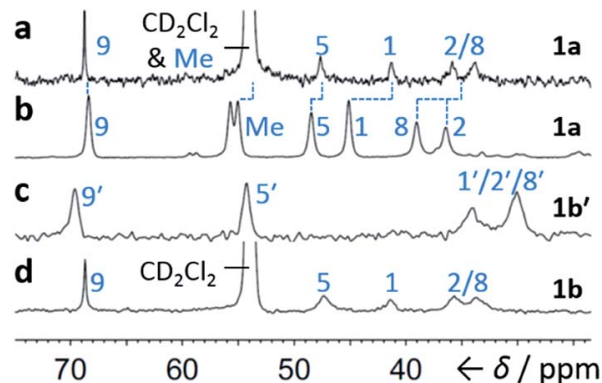

Fig. 4 Comparison of partial ${ }^{13} \mathrm{C}$ NMR spectra of $1 a / 1 a^{\prime}$ and $1 b / 1 b^{\prime}$ acquired ( $a$ and $d$ ) as $\mathrm{CS}_{2}-\mathrm{CD}_{2} \mathrm{Cl}_{2}$ solutions at low temperature (126 $\mathrm{MHz}, 149 \mathrm{~K}$ ), and (b and c) as powders at ambient temperature (105 $\mathrm{MHz}$ ). Peaks are labelled according to the numbering in Scheme 1.

the solid-state NMR (ssNMR) spectrum of the bis(4-anisyl) barbaralane (Fig. 4b), which matches closely with its solution spectra (in keeping with its assignment by X-ray diffraction as structure 1a), the ssNMR spectrum (Fig. 4c) of the bis(4fluorophenyl)barbaralane is markedly different. The ssNMR spectrum indicates structure $\mathbf{1} \mathbf{b}^{\prime}$ is favoured over $\mathbf{1 b}$. Hence, the SSNMR and VT-XRD data are both consistent with the barbaralanes $\mathbf{1} / \mathbf{1}^{\prime}$ having fixed constitutions in the solid state.

The barbaralane cage acts as a hinge between its two aromatic substituents, giving (Fig. 3b) the molecules V-shaped structures. Notably, the dihedral angles between the planes of these aromatic rings in the solid state vary substantially between the different derivatives. Compounds 1a, 1c, and 1d have relatively wide dihedral angles $>67^{\circ}$, whereas the dihedral angles of $\mathbf{1} \mathbf{b}^{\prime}$ and $1 \mathbf{e}^{\prime}$ are both $<44^{\circ}$. $\|$ Inspection (Fig. 5 and S57-S61 $\dagger$ ) of the solid-state superstructures reveals that these changes in dihedral angles are linked to differences in the crystal packing. Indeed, the packing is dominated by the way in which the V-shaped units fit together, rather than any specific noncovalent interactions. Compounds 1a, 1c, and 1d pack with a preference to arrange their V-shaped structures head-to-tail, while $\mathbf{1} \mathbf{b}^{\prime}$ and $\mathbf{1} \mathbf{e}^{\prime}$ are arranged head-tohead, allowing their aromatic groups to interdigitate. We
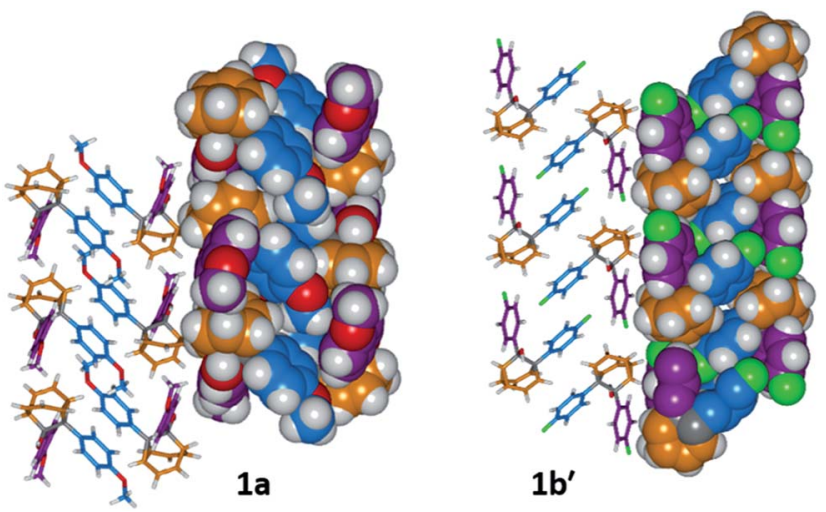

Fig. 5 Solid-state superstructures of $1 \mathrm{a}$ and $1 \mathrm{~b}^{\prime}$ shown in partial stick and space-filling representations and viewed along the crystallographic $b$-axes. The superstructures of $1 c$ and $1 d$ (Fig. S59 and S60 $†$ ) are similar to $1 \mathrm{a}$, whereas the superstructure of $1 \mathrm{e}^{\prime}$ (Fig. S61 $\mathrm{\dagger}$ ) is isostructural with $1 b^{\prime}$. Calculated densities $\left(\mathrm{g} \mathrm{cm}^{-3}\right)$ : $1 \mathrm{a}, 1.33 ; 1 \mathrm{~b}^{\prime}, 1.44 ; 1 \mathrm{c}$, $1.35 ; 1 \mathrm{~d}, 1.35 ; 1 \mathrm{e}^{\prime}, 1.39$ 
attribute changes between these two modes of packing primarily to differences in the sizes of the $\mathrm{R}^{1}$ and $\mathrm{R}^{2}$ groups. A 4-anisyl group is too large to allow efficient interdigitation, so the head-totail arrangement is favoured in which the aromatic rings are splayed around a neighbouring barbaralane. This geometry is most easily accommodated by the $\mathbf{1}$-isomer form. Conversely, $\mathbf{1}^{\prime}$ and $1 \mathrm{e}^{\prime}$ lack 4 -anisyl groups, so they are able to achieve more densely packed lattices than the other derivatives (1.39-1.44 vs. $1.33-1.35 \mathrm{~g} \mathrm{~cm}^{-3}$ ) by adopting head-to-head arrangements. The $4-$ fluorophenyl and phenyl groups are small enough for the aromatic rings to pack together efficiently, favouring smaller dihedral angles that are more accessible when the barbaralane adapts to the slightly higher energy $\mathbf{1}^{\prime}$-isomer. Although there is more strain in the molecular structure, the relatively small $\left(\sim 5 \mathrm{~kJ} \mathrm{~mol}^{-1}\right)$ energy penalty to adopt the structure of the minor solution-state isomer must be overridden by a more favourable lattice energy, making the $\mathbf{1}^{\prime}$-isomer favoured in the solid state. ${ }^{16}$

The alcohol function (which might normally be expected to dictate ${ }^{17}$ the packing) is overcrowded and electrostatic potential maps show (Fig. S66 $\dagger$ ) that the aromatic rings are only mildly polarised. In order to search for noncovalent bonding interactions, we calculated the Hirshfeld surfaces ${ }^{18}$ of each crystal structure. The Hirshfeld surfaces show (Fig. S67-S72†) that no interatomic distances are significantly closer than the sum of the respective van der Waals radii. For example, the most prominent close contacts present (Fig. 6) in $\mathbf{1 d}$ and $\mathbf{1} \mathbf{e}^{\prime}$ are weak $\mathrm{O}-\mathrm{H} \cdots \mathrm{C}$ and $\mathrm{C}-\mathrm{H} \cdots \mathrm{C}$ interactions, which each remain within $\sim 0.2 \AA$ of the sum of the van der Waals radii. ${ }^{19}$ We confirmed this lack of significant, specific noncovalent bonding interactions by performing DFT modelling (CE-B3LYP**) of all the intermolecular interactions in the solid state. These calculations allow us to elucidate the total interaction energies $\left(E_{\text {tot }}\right)$ between neighbouring molecules based on the individual energetic components of electrostatics $\left(E_{\text {ele }}\right)$, polarisation $\left(E_{\text {pol }}\right)$, dispersion forces $\left(E_{\mathrm{dis}}\right)$ and repulsion $\left(E_{\mathrm{rep}}\right){ }^{20}$ For example, we examined (Fig. 7) a cluster of 14 neighbouring molecules surrounding a central molecule in the structure of $1 \mathrm{e}^{\prime}$. The 14 neighbours account for all of the molecules that come within
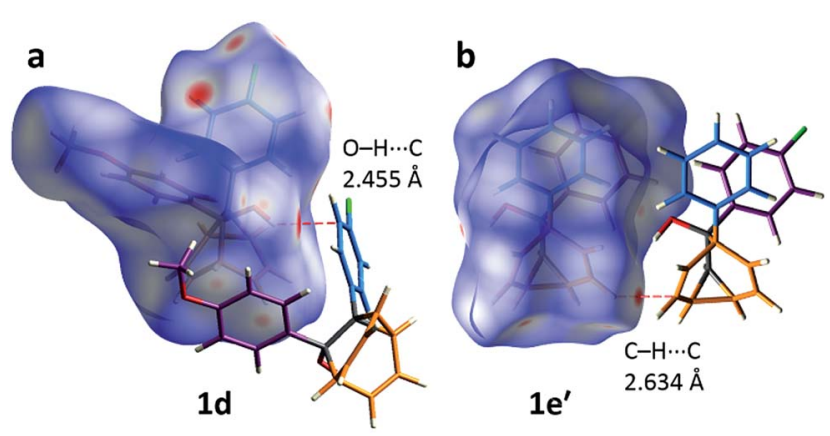

Fig. 6 Calculated Hirshfeld surfaces for the X-ray crystal structures of (a) $1 \mathrm{~d}$ and (b) $1 \mathrm{e}^{\prime}$, showing the most significant close contacts with neighbouring molecules, which do not correspond to appreciable noncovalent bonding interactions.

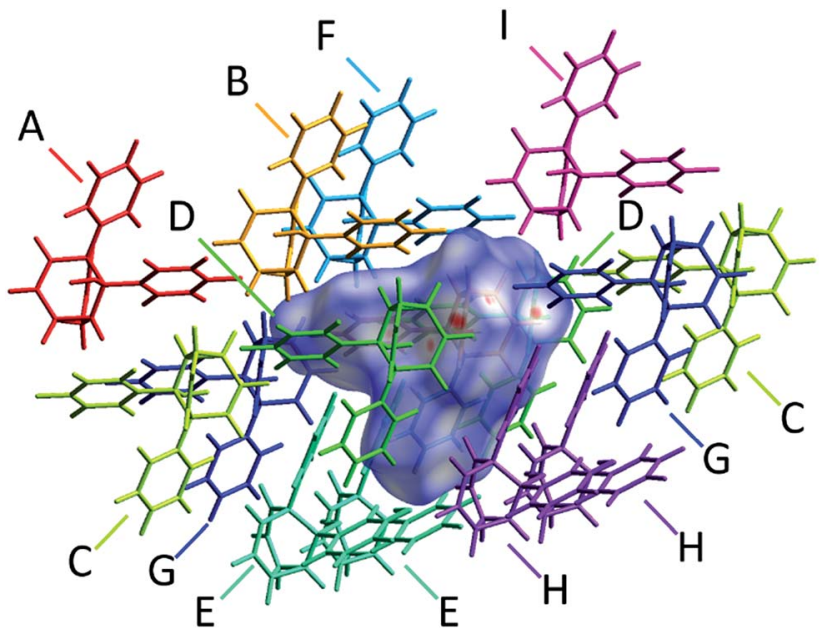

Fig. 7 A section of the solid-state superstructure of $1 e^{\prime}$ in which a central molecule (overlaid with its modelled Hirshfeld surface) is surrounded by its 14 nearest neighbours (labelled A-I). Molecules A-I are shown in stick representation. Labels are duplicated for molecules that reside at symmetry-related coordinates relative to the central molecule.

$3.8 \AA$ of the central molecule. As would be expected, the pairs of $1 \mathrm{e}^{\prime}$ molecules that are closest, having the smallest centroid-tocentroid distances $(R)$, generally interact most strongly with one another. Molecules in position $\mathrm{D}$ and $\mathrm{F}$ are separated (Table 1) from the central molecule by $R<7 \AA$ and have interaction energies of $E_{\text {tot }}=-31.1$ and $-43.5 \mathrm{~kJ} \mathrm{~mol}^{-1}$, respectively, which are the strongest pairings present in the structure. Dispersion forces account for the majority of their attractive intermolecular interactions, contributing energies of $E_{\mathrm{dis}}=$ $-46.8 \mathrm{~kJ} \mathrm{~mol}^{-1}$ for D and $E_{\mathrm{dis}}=-51.4 \mathrm{~kJ} \mathrm{~mol}^{-1}$ for F. Overall, the modelling for the full series of five $\mathbf{1} / \mathbf{1}^{\prime}$ derivatives shows (Tables S10-S14 $\dagger$ ) that dispersion forces ${ }^{21}$ (which are influenced by the shape of the molecules and their packing) make up the major component of the interactions between molecules in all

Table 1 Calculated intermolecular interaction energies $\left(\mathrm{kJ} \mathrm{mol}^{-1}\right)$ for pair of molecules in the solid-state structure of $1 \mathrm{e}^{\prime}$

\begin{tabular}{lrlllll}
\hline & \multicolumn{6}{c}{ Interaction energies $/ \mathrm{kJ} \mathrm{mol}^{-1}$} \\
\cline { 5 - 8 } Neighbouring molecule $^{a}$ & $R / \AA^{b}$ & $E_{\text {ele }}$ & $E_{\text {pol }}$ & $E_{\text {dis }}$ & $E_{\text {rep }}$ & $E_{\text {tot }}{ }^{c}$ \\
\hline A & 13.29 & 2.1 & -0.2 & -1.3 & 0.0 & 1.0 \\
$\mathrm{~B}$ & 7.94 & -10.1 & -1.4 & -31.2 & 20.3 & -26.3 \\
$\mathrm{C}$ & 11.59 & -2.3 & -0.4 & -3.8 & 0.6 & -5.6 \\
$\mathrm{D}$ & 6.20 & -8.4 & -2.4 & -46.8 & 32.8 & -31.1 \\
$\mathrm{E}$ & 8.26 & -5.0 & -0.9 & -30.3 & 18.7 & -20.8 \\
$\mathrm{~F}$ & 6.63 & -14.8 & -2.8 & -51.4 & 30.9 & -43.5 \\
$\mathrm{G}$ & 9.79 & -5.0 & -0.8 & -16.1 & 11.7 & -12.7 \\
$\mathrm{H}$ & 7.90 & -6.3 & -1.1 & -31.5 & 17.9 & -23.8 \\
$\mathrm{I}$ & 11.04 & 1.1 & -0.4 & -8.1 & 1.8 & -5.1
\end{tabular}

${ }^{a}$ The labels A-I correspond to those shown in Fig. 7 and refer to the nearby molecules in the solid state. ${ }^{b} R$ is the centroid-to-centroid distance between the labelled molecule and the central molecule. Centroids are based on the coordinates of all atoms in each molecule and are not weighted by mass. ${ }^{c} E_{\text {tot }}$ is the scaled sum of the individual interaction energy components $E_{\text {ele }}, E_{\mathrm{pol}}, E_{\mathrm{dis}}$ and $E_{\text {rep. }}$. 
of the packing motifs, dominating the overall lattice energies in each case. This observation is consistent with our description of these molecules packing in the solid state in a manner that is influenced more by molecular shape than by any specific noncovalent bonding interactions.

\section{Conclusions}

In summary, by investigating the dynamic isomerisation of nondegenerate barbaralanes, we have found that their crystallisation is directed by the shapes of their fluxional isomers. Either the major or the minor solution-phase isomer may be resolved as a result of their assembly in crystal lattices, becoming trapped in the solid state. At present, it has not been possible to discern precisely the shapes available to the most advanced shapeshifting sensors, ${ }^{6}$ which encompass hundreds of constitutional isomers and conformationally flexible substituents. Our observations, based on a bistable fluxional carbon cage with rigid substituents, illustrate that shapeselective interactions can override the inherent thermodynamic differences between even closely related valence isomers. Understanding the relationship between shape-selectivity and the energetics of fluxional carbon cages will aid the development of shapeshifting sensors and other applications of adaptive molecules.

\section{Conflicts of interest}

There are no conflicts to declare.

\section{Acknowledgements}

A. N. B. acknowledges an EPSRC DTG. J. S. acknowledges an Experientia Foundation Fellowship, Advanced Functional Nanorobots (CZ.02.1.01/0.0/0.0/15_003/0000444 financed by the EFRR), and computational resources from the MSMT under the CESNET (LM2015042) and CERIT-Scientific Cloud (LM2015085) projects. B. M. C. and P. R. M. thank the EPSRC for funding (EP/ N029992/1). We thank Dr Mark Miller and Prof. Jon Steed for useful discussions. We are grateful to Dr David Apperley and Dr Raquel Belda-Vidal for assistance with NMR measurements.

\section{Notes and references}

$\S$ Barbaralanes $\mathbf{1} / \mathbf{1}^{\prime}$ were prepared and isolated as racemic mixtures. For simplicity, only one enantiomer of each compound is shown.

I During our experiments, we did not observe any crystals of solvates or conformational polymorphs. The limited conformational freedom of $\mathbf{1} / \mathbf{1}^{\prime}$ and limited potential for hydrogen bonding suggest they are unlikely to be highly polymorphic.

|| The differences in dihedral angles coincide with changes to the $\mathrm{C} 1-\mathrm{C} 9 / \mathrm{C}^{\prime}-\mathrm{C} 9^{\prime}$ distances in the barbaralane core. The averaged C1-C9 distance for 1a, 1c, and 1d is $1.534 \AA$, whereas the averaged $\mathrm{C5}^{\prime}-\mathrm{C} 9^{\prime}$ distance for $\mathbf{1 b}^{\prime}$ and $\mathbf{1 \mathbf { e } ^ { \prime }}$ is $1.586 \AA$, showing that the movement of the divinylcyclopropane motif influences the geometries near the aromatic rings.

** The CE-B3LYP functional was used instead of other DFT functionals, e.g., CAMB3LYP or MN15-L, because its implementation in CrystalExplorer allows calculation of the individual interaction energy terms in addition to the total energy. It should be noted that CE-B3LYP is different to the original B3LYP functional, which is not suitable for calculation of weak interactions. It reproduces counterpoise-corrected B3LYP-D2/6-31G(d,p) energies with a mean absolute deviation of about $1 \mathrm{~kJ} \mathrm{~mol}^{-1}$ and gives a mean absolute deviation of just $2.5 \mathrm{~kJ} \mathrm{~mol}^{-1}$ compared to $\operatorname{CCSD}(\mathrm{T}) / \mathrm{CBS}$ while using much less computational time. See ref. 20.

1 (a) W. von E. Doering and W. R. Roth, Tetrahedron, 1963, 19, 715; (b) G. Schröder, Angew. Chem., 1963, 75, 722; (c) A. Ault, J. Chem. Educ., 2001, 78, 924; (d) O. Yahiaoui, L. F. Pašteka, B. Judeel and T. Fallon, Angew. Chem., Int. Ed., 2018, 57, 2570.

2 (a) P. Ahlberg, D. L. Harris and S. Winstein, J. Am. Chem. Soc., 1970, 92, 4454; (b) D. Cremer, P. Svensson, E. Kraka and P. Ahlberg, J. Am. Chem. Soc., 1993, 115, 7445; (c) P. R. McGonigal, C. de León, Y. H. Wang, A. Homs, C. R. Solorio-Alvarado and A. M. Echavarren, Angew. Chem., Int. Ed., 2012, 51, 13093; (d) S. Ferrer and A. M. Echavarren, Angew. Chem., Int. Ed., 2016, 55, 11178.

3 S. Jalife, J. I.-C. Wu, G. Martínez-Guajardo, P. von Ragué Schleyer, M. A. Fernández-Herrera and G. Merino, Chem. Commun., 2015, 51, 5391.

4 (a) D. J. Tantillo and R. Hoffmann, Acc. Chem. Res., 2006, 39, 477; (b) J.-M. Lehn, Top. Curr. Chem., 2012, 322, 1.

5 J.-M. Lehn, Angew. Chem., Int. Ed., 2015, 54, 3276.

6 (a) A. R. Lippert, A. Naganawa, V. L. Keleshian and J. W. Bode, J. Am. Chem. Soc., 2010, 132, 15790; (b) K. K. Larson, M. He, J. F. Teichert, A. Naganawa and J. W. Bode, Chem. Sci., 2012, 3, 1825; (c) J. F. Teichert, D. Mazunin and J. W. Bode, J. Am. Chem. Soc., 2013, 135, 11314.

7 C. W. Jefford, J. C. Rossier and J. A. Zuber, Angew. Chem., Int. Ed. Engl., 1982, 21, 549.

8 R. E. Moore, J. A. Pettus and J. Mistysyn, J. Org. Chem., 1974, 39, 2201.

9 E. Pretsch, P. Bühlmann and M. Badertscher, Structure Determination of Organic Compounds, Springer-Verlag, Berlin Heidelberg, 4th edn, 2009, p. 91.

10 Previous investigations have shown the preference of alkyl and aryl substituents to occupy a barbaralane 1-position over a 5-position. J. C. Barborak, S. Chari and P. von Ragué Schleyer, J. Am. Chem. Soc., 1971, 93, 5275. See also ref. $2 d$.

11 (a) R. O. Gould, C. L. Jones, T. A. Stephenson and D. A. Tocher, J. Organomet. Chem., 1984, 264, 365; (b) J. L. Davidson, W. F. Wilson, L. Manojlović-Muir and K. W. Muir, J. Organomet. Chem., 1983, 254, C6-C10; (c) K. M. J. Brands and A. J. Davies, Chem. Rev., 2006, 106, 2711; (d) Y. Kitamoto, K. Suzuki, N. Morohashi, K. Sakai and T. Hattori, J. Org. Chem., 2013, 78, 597; (e) M. Sakamoto and T. Mino, in Advances in Organic Crystal Chemistry: Comprehensive Reviews, ed. R. Tamura and M. Miyata, Springer, Tokyo, 1st edn, 2015, vol. 1, p. 445.

12 Some monosubstituted bullvalenes resolve to single isomers upon crystallisation (a) K. Müller, H. Zimmermann, C. Krieger, R. Poupko and Z. Luz, J. Am. Chem. Soc., 1996, 118, 8006; (b) R. Poupko, K. Müller, C. Krieger, H. Zimmermann and Z. Luz, J. Am. Chem. Soc., 1996, 118, 8015; (c) Z. Luz, L. Olivier, R. Poupko, K. Müller, C. Krieger and H. Zimmermann, J. Am. Chem. Soc., 1998, 120, 5526. 
13 There has been one report of a minor valence isomer crystallising from a solution of a bullvalene derivative. However, the assignment of the major species in the solution-phase equilibrium is somewhat ambiguous and it has not been possible to discern what forces control the crystallisation. P. Luger and K. Roth, J. Chem. Soc., Perkin Trans. 2, 1989, 649.

14 (a) R. D. Miller and C. S. Yannoni, J. Am. Chem. Soc., 1980, 102, 7396; (b) W. W. Win, K. G. Grohmann and L. Todaro, J. Org. Chem., 1994, 59, 2803; (c) J. Siegwarth, J. Bornhöft, C. Näther and R. Herges, Org. Lett., 2009, 11, 3450. See also articles cited in ref. $2 d, 12$ and 13.

15 (a) V. Macho, R. D. Miller and C. S. Yannoni, J. Am. Chem. Soc., 1983, 105, 3735; (b) I. Sellner, H. Schuster, H. Sichert, J. Sauer and H. Nöth, Chem. Ber., 1983, 116, 3751; (c) L. M. Jackman, A. Benesi, A. Mayer, H. Quast, E. M. Peters, K. Peters and H. G. von Schnering, J. Am. Chem. Soc., 1989, 111, 1512; (d) S. Schlick, Z. Luz, R. Poupko and H. Zimmermann, J. Am. Chem. Soc., 1992, 114, 4315; (e) R. V. Williams, V. R. Gadgil, P. Luger, T. Koritsanszky and M. Weber, J. Org. Chem., 1999, 64, 1180; (f) A. Benesi, R. Bertermann, H. Förster, M. Heubes, L. M. Jackman,
T. Koritsanszky, P. Luger, A. Mayer, H. Quast, M. Seefelder and D. Zobel, J. Am. Chem. Soc., 2000, 122, 4455.

16 Differences in lattice energies of $\sim 5 \mathrm{~kJ} \mathrm{~mol}^{-1}$ between conformational polymorphs are relatively common. See $(a)$ P. G. Thompson and G. M. Day, Chem. Sci., 2014, 5, 3173; (b) J. Nyman and G. M. Day, CrystEngComm, 2015, 17, 5154. Even though the isomerisation of the barbaralanes described here causes changes in constitution, rather than just conformation, the energetic differences are of similar magnitude to some conformational changes. It is reasonable, therefore, that the small energetic preference of the fluxional Cope rearrangements can be outweighed upon crystallisation.

17 E. N. Baker and R. E. Hubbard, Prog. Biophys. Mol. Biol., 1984, 44, 97.

18 M. A. Spackman and D. Jayatilaka, CrystEngComm, 2009, 11, 19.

19 R. S. Rowland and R. Taylor, J. Phys. Chem., 1996, 100, 7384. 20 M. J. Turner, S. Grabowsky, D. Jayatilaka and M. A. Spackman, J. Phys. Chem. Lett., 2014, 5, 4249.

21 J. P. Wagner and P. R. Schreiner, Angew. Chem., Int. Ed., 2015, 54, 12274. 